\title{
ASTIGMATISM DECAY IMMEDIATELY FOLLOWING SUTURE REMOVAL
}

\author{
T. POTAMITIS, M. FOULADI, F. EPERJESE and P. J. McDONNELL \\ Birmingham
}

\section{SUMMARY}

In a prospective study of 34 patients with high post-operative astigmatism (mean $6.90 \mathrm{D}$, range 2.75-15.00 D) following extracapsular cataract surgery (13 limbal sections and 21 corneal sections), we used keratometry to assess the changes in corneal curvature seen within 30 minutes of suture removal and compared these with the astigmatism found 2 weeks later. The greatest change occurred within the first 5 minutes of suture removal (mean $3.63 \mathrm{D}$; $95 \%$ confidence interval (95\% CI) 2.85-4.41). The rate of decay then declined so that between 15 and 30 minutes the mean change was 0.56 D (95\% CI 0.43-0.69). At 2 weeks a further mean decay of $1.29 \mathrm{D}(95 \%$ CI 0.99-1.61) occurred. Of the 6 patients exhibiting a residual astigmatism greater than 3.00 D at 30 minutes, 4 continued to do so 2 weeks later. Our study suggests that keratometry 30 minutes following suture removal is only moderately different from that seen 2 weeks later. Although not stable enough to suggest that patients could be routinely refracted within 30 minutes of suture removal, in cases where early visual recovery is essential, such as in monocular patients, it may be reasonable to offer a temporary spectacle correction immediately following suture removal. Furthermore keratometry at $30 \mathrm{~min}-$ utes after suture removal accurately predicts the necessity for further removal of sutures and indicates which patients can be discharged to the care of their own optometrist, making a further hospital visit unnecessary.

Today, with the use of modern microsurgical techniques, extracapsular cataract extraction (ECCE) is a safe and largely predictable procedure. One of its commonest complications, however, remains the occurrence of post-operative astigmatism. This leads to delayed visual rehabilitation and increases the number of post-operative visits and refractions. Although there is an ever-increasing

Correspondence to: T. Potamitis, Department of Ophthalmology, University of Birmingham, Birmingham and Midland Eye Centre, Dudley Road, Birmingham B18 7QU, UK. trend towards phacoemulsification, in the United Kingdom conventional ECCE remains the most frequently used method of cataract surgery. ${ }^{1}$ Postoperative astigmatism continues, therefore, to play an important role in everyday clinical practice.

The causes of high astigmatism following cataract extraction are multiple and include wound construction, intraocular lens tilt and excessive diathermy. By far the most important contributing factor, however, is wound closure and over-tightened sutures. ${ }^{2-5}$ The management of post-operative astigmatism therefore entails the manipulation of sutures, usually requiring removal for high with-the-rule astigmatism. The effects of suture removal on post-operative refraction have been studied extensively but always in the time frame of weeks or months following removal. We assessed the change in astigmatism induced within 30 minutes of suture removal, in patients who had undergone conventional ECCE.

\section{PATIENTS AND METHOD}

Thirty-four patients, 15 male and 19 female (mean age 77 years, range 49-94 years), having suture removal for the relief of post-operative astigmatism were recruited into the study. All had undergone uncomplicated conventional ECCE. Thirteen had limbal sections and 21 had corneal sections. All patients had been sutured using five interrupted 10/0 nylon sutures. Suture removal was performed at the slit lamp between 8 and 14 weeks post-operatively. After instilling benoxinate $0.4 \%$ drops in the eye, sutures were cut using a $25 \mathrm{G}$ needle and removed with suture-tying forceps. All sutures were removed uneventfully and with minimal discomfort. Patients had keratometry performed before suture removal and 5 minutes, 15 minutes, 30 minutes and 2 weeks after suture removal. We assessed the decay of astigmatism by comparing the data obtained before suture removal with that obtained 5 minutes, 15 minutes to 30 minutes and 30 minutes to 2 weeks after suture removal. A comparison was made 
Table I. Change in corneal astigmatism following suture removal

\begin{tabular}{lccc}
\hline & \multicolumn{3}{c}{ Time from suture removal } \\
\cline { 2 - 4 } & 5 minutes & From 15 to 30 minutes & From 30 minutes to 2 weeks \\
\hline Mean change in cylinder power (dioptres) & 3.63 & 0.56 & 1.29 \\
$(95 \%$ CI $)$ & $(2.85-4.41)$ & $0.43-0.69)$ & $(0.99-1.61)$ \\
Mean change in cylinder axis (degrees) & 29.97 & 6.71 & 11.77 \\
$(95 \% \mathrm{CI})$ & $(19.91-40.03)$ & $(5.16-7.26)$ & $(10.84-12.76)$ \\
\hline
\end{tabular}

between patients with corneal and limbal sections. The effects of suture removal before and after the tenth post-operative week were also examined.

Student's $t$-test was used for statistical analysis and a $p$ value of less than 0.05 was considered significant.

\section{RESULTS}

Post-operative astigmatism ranged from 3.00 dioptres (D) to $15.25 \mathrm{D}$ (mean $6.50 \mathrm{D}$ ). There was no significant difference between patients with corneal sections (mean 6.40 D, range 3.0-15.0 D) and patients with limbal sections (mean $6.70 \mathrm{D}$, range $3.25-10.50 \mathrm{D})(p=0.37)$. The greatest change in both cylindrical value and axis occurred within 5 minutes of suture removal. A substantially lower rate of astigmatic decay was seen between 15 minutes and 30 minutes following suture removal (Table I; Figs. 1, 2 ). The greater the initial astigmatism, the greater the change induced by suture removal (Fig. 1). A comparison of the astigmatic power found at 30 minutes and at 2 weeks after suture removal revealed a mean change of $1.29 \mathrm{D}$ (95\% confidence interval (95\% CI) 0.99-1.61). The decay during this 2 week period was higher in the corneal section group (mean $1.49 \mathrm{D}, 95 \%$ CI 1.04-1.94) than in the limbal section group (mean $0.96 \mathrm{D}, 95 \%$ CI $0.65-1.27$ ), but this difference did not reach statistical significance $(p=0.11)$. The mean change in cylinder axis during the same 2 week period was $11.77^{\circ}(95 \%$ CI $10.84-12.76)$ for the whole group, $10.64^{\circ}(95 \%$
CI 7.67-13.61) for the corneal group and $13.69^{\circ}$ (95\% CI 12.04-19.34) for the limbal group. The difference between the latter two groups was not statistically significant $(p=0.30)$. The 20 patients having suture removal within 10 weeks of surgery exhibited a greater change in corneal astigmatism (mean power change $1.56 \mathrm{D}$, mean axis change $14.4^{\circ}$ ) than the patients who had suture removal between 10 and 14 weeks after surgery (mean power change $1.08 \mathrm{D}$, mean axis change $\left.9.75^{\circ}\right)$. This difference was not significant however $(p=0.07$ for power and $p=$ 0.10 for axis). Of the 6 patients exhibiting a residual astigmatism greater than $3.00 \mathrm{D} 30$ minutes after suture removal, 4 continued to do so 2 weeks later and required further suture removal.

\section{DISCUSSION}

Refraction following conventional extracapsular cataract extraction may be unstable for at least 2 years ${ }^{6,7}$ and surgical wound remodelling has been shown to continue for some $2 \frac{1}{2}$ years after surgery. ${ }^{8}$ It follows, therefore, that spectacles prescribed immediately following surgery are of temporary use and will tend to need frequent changing if the patient's visual potential is to be maximised. A balance needs to be maintained between the added cost of prescribing too early and the inconvenience of delayed visual rehabilitation.

Our study shows that the rate of decay of postoperative astigmatism following suture removal

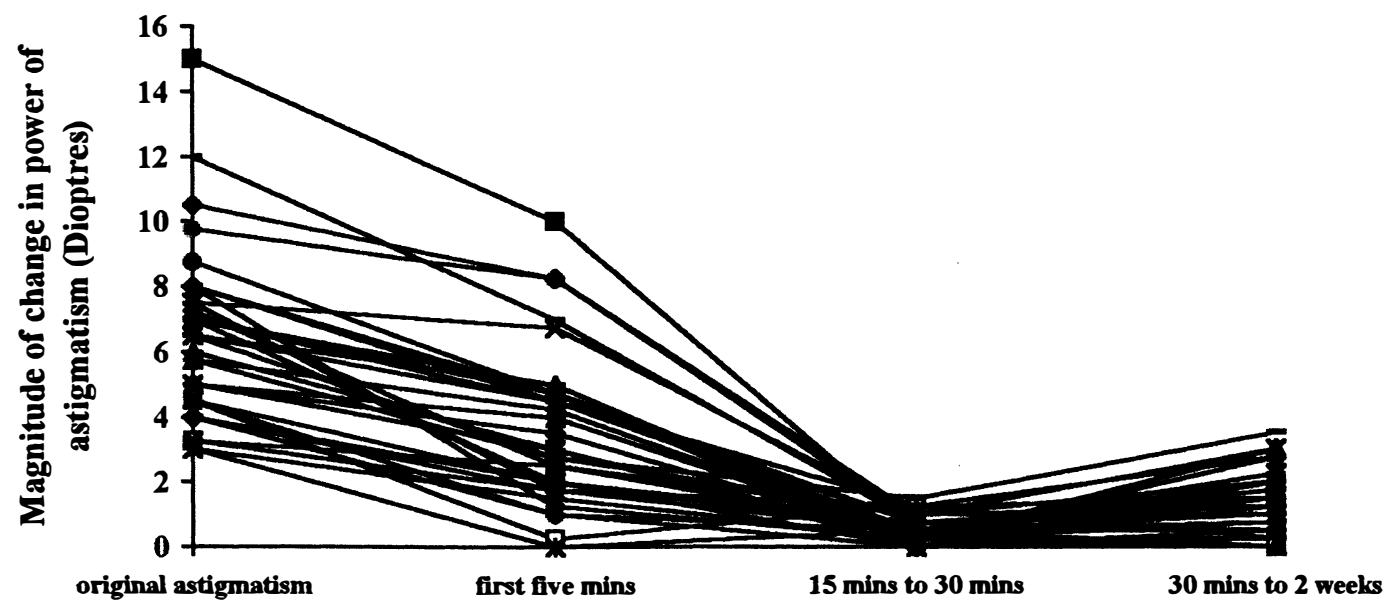

Time period over which change occurred

Fig. 1. Magnitude of change in power of astigmatism following suture removal. Each line represents a different patient. The greatest change occurred in the first 5 minutes. 


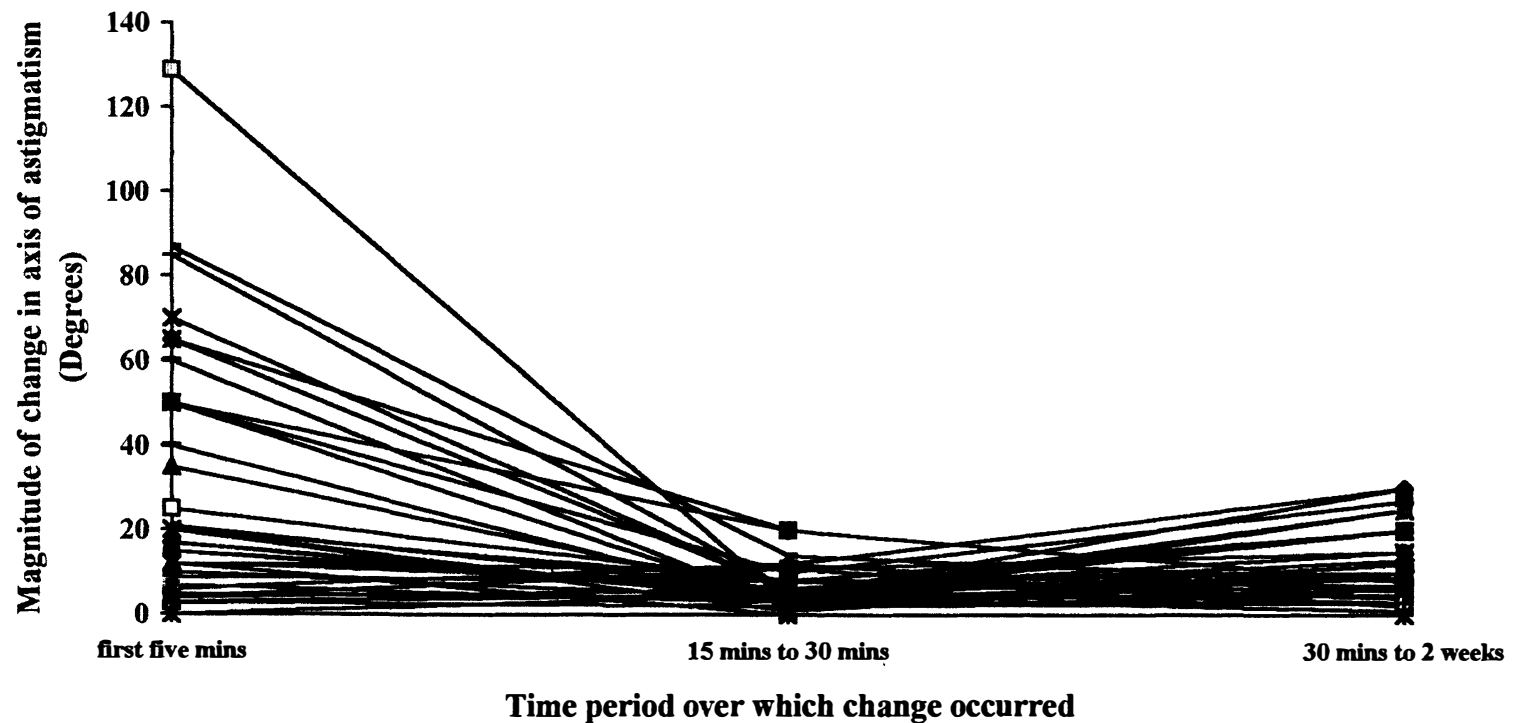

Fig. 2. Magnitude of change in axis of astigmatism following suture removal. Each line represents a different patient. The greatest change occurred in the first 5 minutes.

decreases exponentially, with the maximum change occurring in the first 5 minutes. Keratometry 30 minutes following suture removal is only moderately different from that seen 2 weeks later, with a mean change in cylinder power of $1.29 \mathrm{D}$ and in cylinder axis of $11.77^{\circ}$. Although not stable enough to suggest that patients could be routinely refracted within 30 minutes of suture removal, in cases where early visual recovery is essential, such as in monocular patients, it may be reasonable to offer a temporary spectacle correction immediately following suture removal. What is perhaps of more practical use is the fact that keratometry 30 minutes after suture removal is a good indicator of the residual cylinder found 2 weeks later. If the 30 minute keratometric reading is satisfactory it is unlikely that the patient will require further suture removal and he or she can therefore be discharged to the care of their own optometrist. In the long term, following largeincision cataract surgery there tends to be a shift towards against-the-rule astigmatism. It is important, therefore, to allow for this shift and not to overcorrect with-the-rule astigmatism in the immediate post-operative period. Furthermore sutures may require removal to prevent long-term complications other than astigmatism. This is particularly the case in corneal incisions. We did not specifically design our study to address the issue of timing of suture removal but it is surprising that the changes in corneal curvature are not significantly influenced by the timing of suture removal; this has not been the experience of other workers. ${ }^{9}$

Although it is likely that conventional extracapsular cataract surgery will gradually be replaced by smallincision techniques such as phacoemulsification, at present it forms the bulk of the surgical workload of most ophthalmic units in the United Kingdom. ${ }^{1}$ The occurrence of post-operative astigmatism, and its management, therefore plays a key role in everyday ophthalmic practice. The trend towards day case surgery, early post-operative out-patient discharge and 'shared care' all influence both patient management and expectations. The additional cost and inconvenience caused by repeated out-patient visits and refractions can no longer be ignored. If a patient with high post-operative astigmatism can be treated and discharged on the same visit the adverse effect on the patient's visual recovery is minimised and the cost of patient care reduced.

Key words: Astigmatism, Decay, Suture removal.

\section{REFERENCES}

1. Courtney P. The national cataract surgery survey. I. Method and descriptive features. Eye 1992;6:487-92.

2. Stainer GA, Binder PS, Parker WT, Perl T. The natural and modified course of post-cataract astigmatism. Ophthalmic Surg 1982;13:822-7.

3. Gorn RA. Surgically induced astigmatism and its spontaneous regression. Ophthalmic Surg 1985;16: $162-4$.

4. Jaffe NS, Clayman HM. The pathophysiology of corneal astigmatism after cataract extraction. Ophthalmology 1975;79:615-30.

5. Wishart MS, Wishart PK, Gregor ZJ. Corneal astigmatism following cataract extraction. Br J Ophthalmol 1986;70:825-30.

6. Baranyovits P. Stabilisation of refraction following extracapsular cataract extraction. $\mathrm{Br} \mathrm{J}$ Ophthalmol 1990;74:486-9.

7. Parker WT, Clorfeine GS. Long-term evolution of astigmatism following planned extracapsular cataract extraction. Arch Ophthalmol 1989;107:353-7.

8. Flaxel JT, Swan KC. Limbal wound healing after cataract extraction. Arch Ophthalmol 1969;81:653-9.

9. Stanford MR, Fenech T, Hunter PA. Timing of removal of sutures in control of post-operative astigmatism. Eye $1993 ; 7: 143-7$ 